\section{Lewis Base Assisted Lithium Brønsted Base Catalysis: A New Entry for Catalytic Asymmetric Synthesis of $\beta^{2,2}$-Amino Acids}

\author{
Fuyuki Amemiya, Hidetoshi Noda,* and \\ Masakatsu Shibasaki*
}

Institute of Microbial Chemistry, Tokyo; 3-14-23 Kamiosaki, Shinagawa-ku, Tokyo 141-0021, Japan.

Received July 10, 2019; accepted July 16, 2019; advance publication released online July 25, 2019

A new catalytic system comprising chiral Ag complex and $\mathrm{Li}$ aryloxide/bisphosphine oxide is developed for the synthesis of $\beta^{2,2}$-amino acids via direct asymmetric Mannich-type reaction of 4-subsituted isoxazolidin-5-ones. The Mannich adduct is a direct precursor of $\beta$-peptidic compounds otherwise difficult to obtain.

Key words asymmetric catalysis; Lewis base; $\beta$-amino acid; Mannich reaction

\section{Introduction}

$\beta$-Amino acids are major structural constituents of peptidomimetics, which are receiving growing attention from the community. ${ }^{1)}$ They are also found in many other biologically active compounds, most notably in $\beta$-lactam antibiotics. ${ }^{2)} \mathrm{Un}$ like natural $\alpha$-amino acids, many $\beta$-variants have to be synthesized chemically. Therefore, catalytic asymmetric synthesis of $\beta$-amino acids has been a topic of extensive research for the last two decades. ${ }^{3)}$ Despite such tremendous efforts, only limited methods are available for the synthesis of $\beta^{2,2}$-amino acids, which are geminally disubstituted at the $\alpha$-carbon. Hence, the development of a new method for synthesizing allcarbon quaternary analogs are highly sought after. ${ }^{4,5)}$

$\alpha$-Functionalization of amino acid derived enolates is one of the most straightforward approaches to $\beta^{2,2}$-amino acids. ${ }^{6}$ Isoxazolidin-5-ones have been used as precursors for $\beta$-amino acids through the reductive cleavage of the $\mathrm{N}-\mathrm{O}$ bond. ${ }^{7)} \mathrm{Al}-$ though chiral auxiliary based diastereoselective approaches have been reported in the literature to control the chirality at the $\alpha$-carbon of isoxazolidin-5-ones, ${ }^{8-10)}$ catalytic asymmetric construction of the all carbon quaternary center from racemic substrates has only recently evolved. ${ }^{11)}$ Since our first demonstration on the catalytic asymmetric decarboxylative allylation of substituted isoxazolidin-5-ones, ${ }^{12}$ a major challenge in this research field lies in the direct use of enolate precursors for a highly enantioselective catalytic transformation. Cossy and colleagues disclosed the allylic alkylations of 4-aryl isoxazolidin-5-ones promoted by a chiral Pd catalyst together with stoichiometric amount of $\mathrm{Na}_{2} \mathrm{CO}_{3}{ }^{13)}$ (Chart 1a). Based on their $\alpha$-sulfanylation of isoxazolidin-5-ones, ${ }^{14)}$ the Brière group documented the use of a combination of a chiral phase transfer catalyst (PTC) and stoichiometric amount of $\mathrm{Cs}_{2} \mathrm{CO}_{3}$ for the conjugate addition of 4-alkyl substrates ${ }^{15)}$ (Chart 1b). Recently, Waser and colleagues also presented a similar PTC-based catalytic system for the allylation of a carbonate derived from Morita-Baylis-Hillman adducts using 4-benzyl substrates ${ }^{16}$ (Chart 1c). Although the reaction produced enantioenriched products in good yields, all the precedents above necessitated stoichiometric amount of Brønsted base to promote the catalytic reactions. Given the long-standing interests in

a) Arseniyadis \& Cossy (2018)<smiles>[R]C(=C)COC(C)=O</smiles>

b) Brière (2018)<smiles>CCCCCCCC</smiles>

c) Waser (2018)<smiles>C=C(CC)C(Br)OCC</smiles>

d) Shibasaki (2018)<smiles>[R]c1cccc2c1N(C)C(=O)C2=NC(C)(C)C</smiles>

e) This work<smiles>CC(C)(C)N=CBr</smiles><smiles>O=C1CN(CC2CCCCC2)C(=O)O1</smiles>

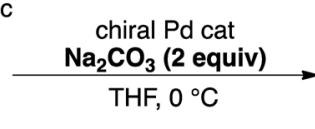<smiles>O=C1ON(C(=O)c2ccccc2)CC1CP</smiles>

chiral PTC cat $\mathrm{Cs}_{2} \mathrm{CO}_{3}$ (1.1 equiv) $\mathrm{THF},-20^{\circ} \mathrm{C}$

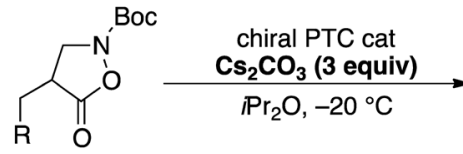<smiles>COC(=O)N1CC([Al])C(=O)O1</smiles><smiles>Cc1cccc(C(NC(=O)OC(C)(C)C)(C(=O)NC(=O)OC(C)(C)C)C2([Te])CN(C(=O)OC(C)(C)C)CC2=O)c1</smiles><smiles>[2H]CC1CN(C(=O)OC(C)(C)C)CC1C</smiles><smiles>[R]C(=C)C[C@@]1(Br)CN(C(=O)OC(C)(C)C)C(=O)O1</smiles><smiles>CC(C)(C)OC(=O)N1C[C@](CP)(CCCN(C(=O)OC(C)(C)C)C(=O)c2ccccc2)C(=O)O1</smiles><smiles>CCOC(=O)c1ccccc1CC1(CC(C)=C[Al])CN(C(=O)OC(C)(C)C)C(=O)OC1=O</smiles><smiles>[3H]CC1(C([Al])NC(=O)OC(C)(C)C)CN(C(=O)OC(C)(C)C)C(=O)O1</smiles>

Chart 1. Direct Catalytic Asymmetric Transformations of 4-Substituted Isoxazolidin-5-ones for the Synthesis of Quaternary $\beta^{2,2}$-Amino Acids 
Table 1. Optimization of Mannich Reaction of Isoxazolidin-5-one $\mathbf{1 a}^{a)}$

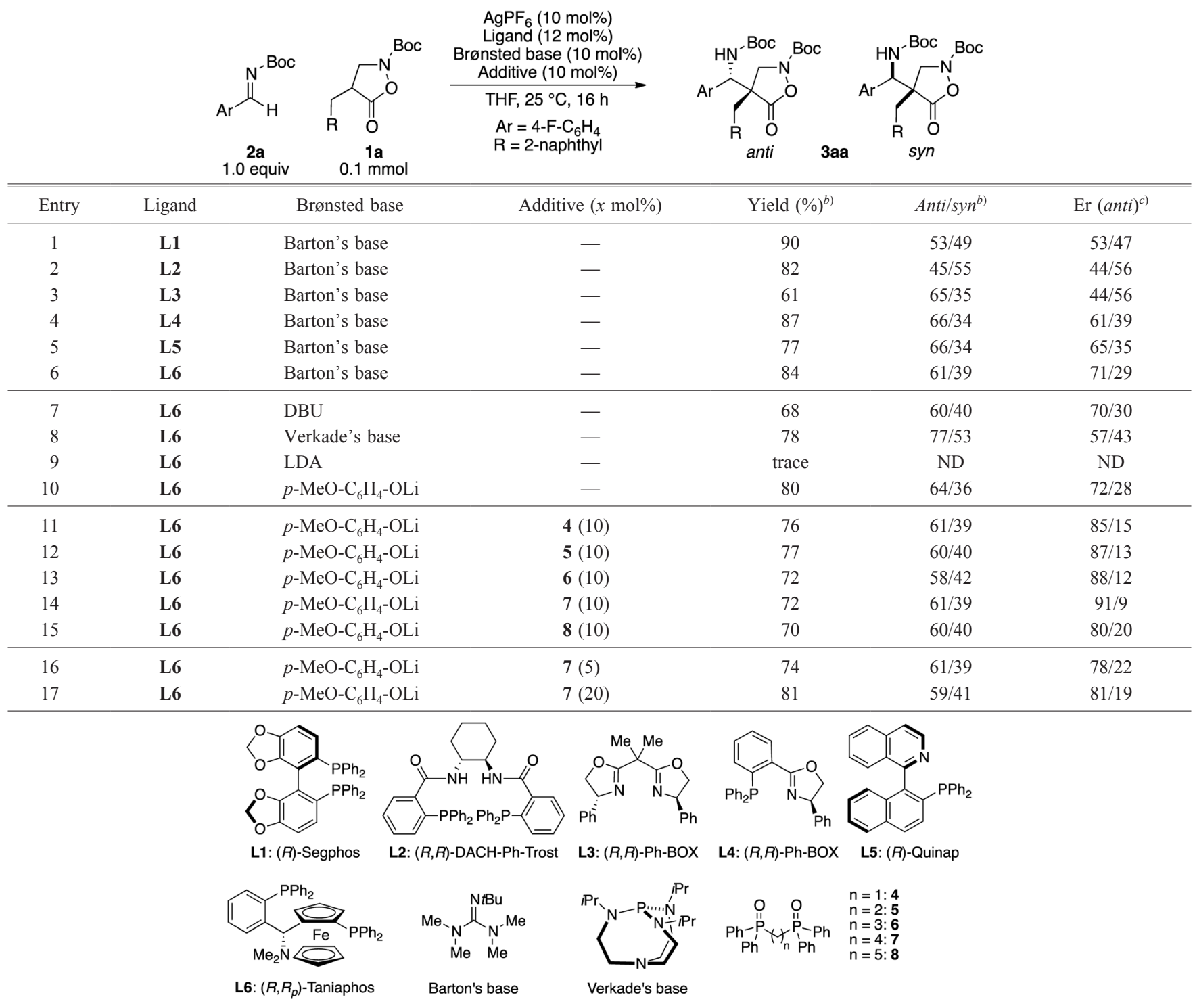

a) 2a (1.0 equiv), 1a $(0.1 \mathrm{mmol})$, THF $\left.(0.1 \mathrm{M}), 25^{\circ} \mathrm{C}, 16 \mathrm{~h} . b\right)$ Yield and diastereomer ratio were determined by ${ }^{1} \mathrm{H}-\mathrm{NMR}$ analysis of the unpurified reaction mixture. $\left.c\right)$ Enantiomer ratio of the anti-isomer was determined with normal phase HPLC on a chiral support. DBU: 1,8-diazabicyclo[5.4.0]undec-7-ene, LDA: lithium diisopropyl amide.

direct enolization chemistry, ${ }^{17)}$ we aimed at the development of a truly catalytic system, and reported the organocatalyzed direct Mannich-type reaction using 4-aryl substrates ${ }^{18)}$ (Chart 1d). Despite the high selectivities, 4-aryl groups were essential for enhancing the acidity of the $\alpha$-proton because of the low basicity of the cinchona alkaloid catalyst-no reaction was observed with the corresponding 4-alkyl substrates under otherwise identical conditions. This Communication introduces a new catalytic system suitable for expanding the nucleophile scope to 4-benzyl substrates in the direct catalytic asymmetric Mannich-type reaction to Boc-aldimines (Chart 1e).

\section{Results and Discussion}

From the outset, we realized that a stronger Brønsted base was required to generate the corresponding enolate from 4-alkyl substrates. Inclusion of a Lewis acid was also expected to be beneficial for tuning the reactivity of an electrophile and controlling the chiral environment around the reactants. A quick examination of various metal Lewis acids revealed that the combination of a silver salt with Barton's base was effective in promoting the Mannich-type reaction of 1a to Boc-aldimine 2a (see the Supplementary Materials for details). Table 1 displays the summary of the optimization study. While $C_{2}$-symmetric bisphosphine and bisoxazoline ligands barely induced any selectivity (entries 1-3), a series of P,Nligands exhibited moderate enantioselectivities, among which L6 was the most promising (entries 4-6). Hence, other Brønsted bases were examined with ligand L6. An amidine base, 1,8-diazabicyclo[5.4.0]undec-7-ene (DBU), exhibited selectivity comparable to that of Barton's base (entry 7), whereas a class of organosuperbase, Verkade's base, ${ }^{19)}$ gave lower selectivities (entry 8). Two lithium-based Brønsted bases examined showed distinctive results: while lithium diisopropylamide (LDA) only produced trace amount of the product, a lithium aryloxide showed similar reactivity and selectivities as those of Barton's base (entries 9,10). The substantial volume of literature on the use of a Lewis basic additive to stoichiometric lithium base encouraged us to examine a series of achiral 
Table 2. Scope of Direct Catalytic Mannich-Type Reaction of Isoxazolidin-5-ones ${ }^{a)}$

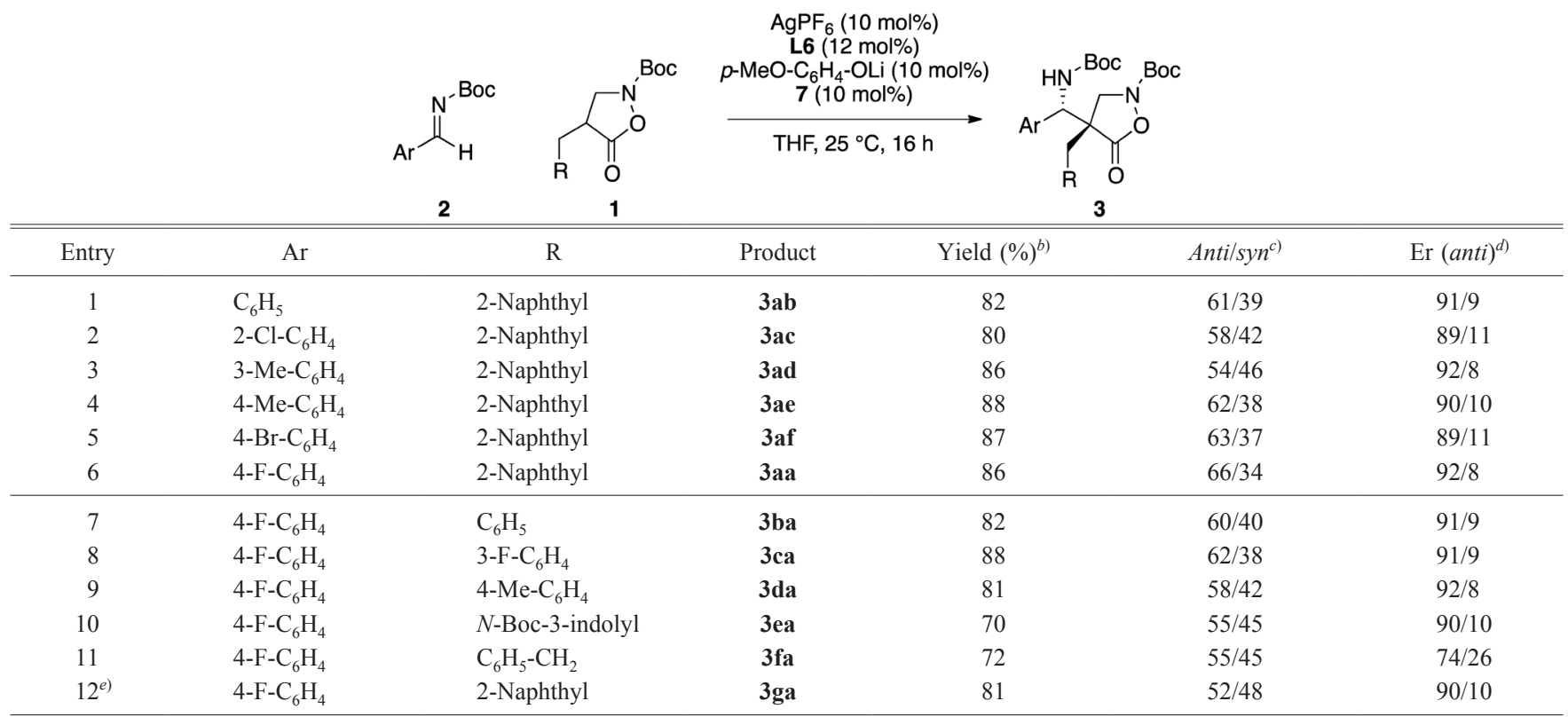

a) $\mathbf{2}$ (1.0 equiv), $\mathbf{1}(0.2 \mathrm{mmol})$, THF $\left.(0.1 \mathrm{M}), 25^{\circ} \mathrm{C}, 16 \mathrm{~h} . b\right)$ Yield values refer to isolated yield. $c$ ) Diastereomer ratio was determined by ${ }^{1} \mathrm{H}-\mathrm{NMR}$ analysis of the unpurified reaction mixture. $d$ ) Enantiomer ratio of the anti-isomer was determined with normal phase HPLC on a chiral support. $e$ ) The reaction was performed with $N$-Cbz-protected isoxazolidin-5-one.

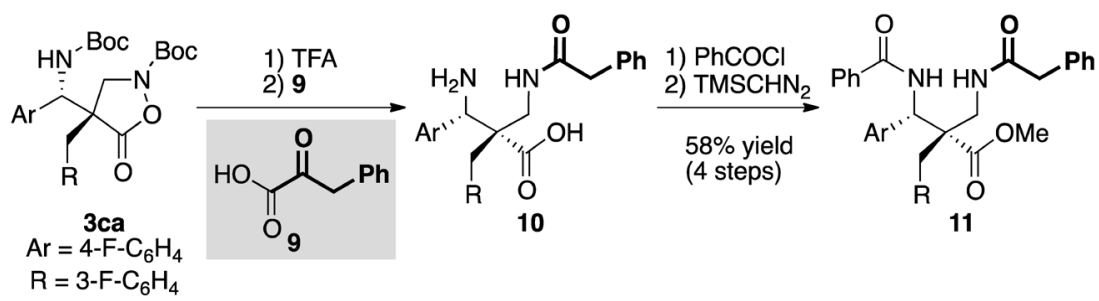

Chart 2. Transformation of the Mannich Adduct

bisphosphine oxides with varied linker lengths as an additive to the lithium (entries $11-15){ }^{20-22)}$ Dramatic improvement on the enantioselectivities was observed by the inclusion of phosphine oxides, and 7 provided the best selectivities and reactivity. Changing the ratio of the lithium base to 7 suggested that the additive coordinated to the Brønsted base in 1:1 stoichiometry (entries 16, 17). While the anti product was obtained in good enantioselectivity under the optimized conditions, the syn product was produced in almost racemic form $(51: 49 \mathrm{er}$, entry 14, Table 1).

Having identified the suitable catalytic conditions (entry 14 Table 1), we examined a range of combinations of 4-substituted isoxazolidin-5-ones and Boc-aldimines (Table 2). Both ortho- and meta-substituted aromatic imines gave similar enantioselectivities irrespective of the nature of the substituents (entries 1-3). The same trend was observed for para-substituted imines, and products having a methyl group (3ae) or a halogen (3af, 3aa) were obtained in good enantioselectivities (entries 4-6). These reaction conditions were also compatible with various $\alpha$-substituents of isoxazolidin-5-ones. Both electron withdrawing and donating groups can be present at either the meta- or para-position on the aromatic ring for producing the corresponding products with the same level of selectivities (entries 7-9). Furthermore, protected indole was also tolerated in the reaction (entry 10). Homologation by a methylene unit at the $\alpha$-position, however, led to lower enantioselectivity (entry 11). The protecting group of the isoxazolidin-5-one was not limited to Boc group, and a Cbz derivative also produced the corresponding product in good enantioselectivity (entry 12). The relative configuration of Mannich adduct 3aa was determined by nuclear Overhauser effect (NOE) analyses after derivatizations, and the absolute configuration was determined by the Mosher method. ${ }^{23,24)}$ The stereochemistry of other products was assigned by analogy.

Two Boc-protected nitrogen atoms in the product are chemically distinctive and can be readily differentiated. For instance, after removing the Boc groups, treatment with $\alpha$-ketoacid 9 triggered a decarboxylative amide formation with the hydroxylamine moiety in a chemoselective fashion. ${ }^{25}$ ) The remaining primary amine was acylated with benzoyl chloride, followed by the formation of methyl ester to afford $\mathbf{1 1}$ in a good overall yield (Chart 2).

\section{Conclusion}

In summary, we have devised a new catalytic reaction for the synthesis of $\beta^{2,2}$-amino acids via direct Mannich-type reaction. The catalytic system comprises a chiral Ag complex and a lithium Brønsted base ligated with a bisphosphine oxide, accommodating a range of benzyl-type substituents at the 4-position of isoxazolidin-5-ones. The obtained Mannich adducts were direct precursors of $\beta$-peptidic compounds otherwise difficult to obtain. Our current efforts aim for the de- 
velopment of a chiral catalytic system with higher selectivity for a broad range of transformations with isoxazolidin-5-ones.

Acknowledgments This research was financially supported by JST, ACT-C (JPMJCR12YO), and JSPS KAKENHI Grant Number JP18K14878. We are grateful to Dr. Ryuichi Sawa, Yumiko Kubota, Dr. Kiyoko Iijima, and Yuko Takahashi for NMR and MS analyses.

Conflict of Interest The authors declare no conflict of interest.

Supplementary Materials The online version of this article contains supplementary materials.

\section{References}

1) Cabrele C., Martinek T. A., Reiser O., Berlicki Ł., J. Med. Chem., 57, 9718-9739 (2014).

2) Bush K., Macielag M. J., Expert Opinion on Therapeutic Patents, 20, 1277-1293 (2010).

3) Weiner B., Szymański W., Janssen D. B., Minnaard A. J., Feringa B. L., Chem. Soc. Rev., 39, 1656-1691 (2010).

4) Badiola E., Olaizola I., Vázquez A., Vera S., Mielgo A., Palomo C., Chem. Eur. J., 23, 8185-8195 (2017).

5) Diaz-de-Villegas M. D., Gálvez J. A., Badorrey R., López Ram de Víu P., Adv. Synth. Catal., 356, 3261-3288 (2014).

6) Jautze S., Peters R., Synthesis, 2010, 365-388 (2010).

7) Baldwin J. E., Harwood L. M., Lombard M. J., Tetrahedron, 40, 4363-4370 (1984).

8) Ishikawa T., Nagai K., Kudoh T., Saito S., Synlett, 1995, 1171-1173 (1995).
9) Bentley S. A., Davies S. G., Lee J. A., Roberts P. M., Russell A. J., Thomson J. E., Toms S. M., Tetrahedron, 66, 4604-4620 (2010).

10) Shindo M., Ohtsuki K., Shishido K., Tetrahedron Asymmetry, 16, 2821-2831 (2005).

11) Annibaletto J., Oudeyer S., Levacher V., Brière J.-F., Synthesis, 49, 2117-2128 (2017).

12) Yu J.-S., Noda H., Shibasaki M., Angew. Chem. Int. Ed., 57, 818822 (2018).

13) Nascimento de Oliveira M., Arseniyadis S., Cossy J., Chem. Eur. J., 24, 4810-4814 (2018).

14) Cadart T., Berthonneau C., Levacher V., Perrio S., Brière J.-F., Chem. Eur. J., 22, 15261-15264 (2016).

15) Cadart T., Levacher V., Perrio S., Brière J.-F., Adv. Synth. Catal., 360, 1499-1509 (2018).

16) Capaccio V., Zielke K., Eitzinger A., Massa A., Palombi L., Faust K., Waser M., Org. Chem. Front., 5, 3336-3340 (2018).

17) Yamada Y. M. A., Yoshikawa N., Sasai H., Shibasaki M., Angew. Chem. Int. Ed. Engl., 36, 1871-1873 (1997).

18) Yu J.-S., Noda H., Shibasaki M., Chem. Eur. J., 24, 15796-15800 (2018).

19) Kisanga P. B., Verkade J. G., Schwesinger R., J. Org. Chem., 65, 5431-5432 (2000).

20) Collum D. B., McNeil A. J., Ramirez A., Angew. Chem. Int. Ed., 46, 3002-3017 (2007).

21) Morimoto H., Yoshino T., Yukawa T., Lu G., Matsunaga S., Shibasaki M., Angew. Chem. Int. Ed., 47, 9125-9129 (2008).

22) Iwata M., Yazaki R., Chen I.-H., Sureshkumar D., Kumagai N., Shibasaki M., J. Am. Chem. Soc., 133, 5554-5560 (2011).

23) Dale J. A., Mosher H. S., J. Am. Chem. Soc., 95, 512-519 (1973).

24) Ohtani I., Kusumi T., Kashman Y., Kakisawa H., J. Am. Chem. Soc., 113, 4092-4096 (1991).

25) Bode J. W., Fox R. M., Baucom K. D., Angew. Chem. Int. Ed., 45, $1248-1252$ (2006). 